University of Nebraska - Lincoln

DigitalCommons@University of Nebraska - Lincoln

To Improve the Academy

Professional and Organizational Development Network in Higher Education

1997

\title{
Designing Effective Group Activities: Lessons for Classroom Teaching and Faculty Development
}

\author{
Larry K. Michaelsen \\ University of Central Missouri, Imichaelsen@ucmo.edu \\ L. Dee Fink \\ Arletta Knight
}

Follow this and additional works at: https://digitalcommons.unl.edu/podimproveacad

Part of the Higher Education Administration Commons

Michaelsen, Larry K.; Fink, L. Dee; and Knight, Arletta, "Designing Effective Group Activities: Lessons for Classroom Teaching and Faculty Development" (1997). To Improve the Academy. 385.

https://digitalcommons.unl.edu/podimproveacad/385

This Article is brought to you for free and open access by the Professional and Organizational Development Network in Higher Education at DigitalCommons@University of Nebraska - Lincoln. It has been accepted for inclusion in To Improve the Academy by an authorized administrator of DigitalCommons@University of Nebraska - Lincoln. 
Michaelsen, L. K., Fink, L. D., \& Knight, A. (1997). Designing effective group activities: Lessons for classroom teaching and faculty development. In D. DeZure (Ed), To Improve the Academy, Vol. 16 (pp. 373-398). Stillwater, OK: New Forums Press and the Professional and Organizational Development Network in Higher Education. Key Words: Active Learning, Cooperative Learning, Claseroom Management, Group Development, Instructional Strategies, Peer Teaching, Team Leaning, Workshops.

\section{Designing Effective Group Activities: Lessons for Classroom Teaching and Faculty Development}

\section{Larry K. Michaelsen}

\section{Dee Fink}

\section{Arletta Knight}

The University of Oklahoma

The primary objective of this article is to provide readers with guidance for designing effective group assignments and activities for classes and workshops. In doing so, we examine the forces that foster social loafing (uneven participation) in learning groups and identify four key variables that must be managed in order to create a group environment that is conducive for broad-based member participation and learning. We then discuss the impact of various types of activities and assignments on learning and group cohesiveness. Finally, we present a checklist that has been designed to evaluate the effectiveness of group assignments in a wide variety of instructional settings and subject areas. 
Over the last few years, group activities have become increasingly popular. However, instructors and workshop leaders frequently report three common problems that greatly reduce the effectiveness of smallgroup learning activities. Two of the three problems typically occur while students or workshop participants are actually engaged in the group work. Probably the most common problem is that one or two vocal individuals often dominate the discussions to the point that quieter members' ideas are either unexpressed or largely ignored. Alternatively, groups frequently have difficulty staying focused on the assigned task because they get side-tracked on inconsequential or irrelevant details. The third problem occurs when groups are reporting the results of their work to the total class. Even when there has been a high level of engagement in the small groups, subsequent wholeclass discussions sometimes "fall flat."

Based on our experience, these "problems" are actually symptoms that are almost always the result of poorly conceived group tasks. Further, we believe that all three of these problems can be avoided if classroom teachers and faculty developers use activities that are designed to take into account: (1) the developmental level of the groups in which they will be used and (2) the impact of the activity on the cohesiveness of the groups.

With this in mind, our primary objective in writing this article is to provide a set of conceptual tools to provide guidance for designing effective group assignments and activities for classes and workshops. Overall, the most important idea in the paper is that the most reliable way to gauge the learning value of group assignments is to examine their impact on group cohesiveness. Accordingly, a second objective in writing the article is to help readers understand how different types of learning tasks contribute to or detract from group cohesion.

In the pages that follow, we:

1. discuss the psychological processes that result in uneven participation by group members;

2. identify four key variables that must be managed in order to create a group environment that is conducive for broad-based member participation and learning; 
3. describe the cognitive processes through which learning occurs and discuss the implications for designing effective learning activities;

4. outline the impact of assignment wording on learning and group development;

5. present a checklist for evaluating and/or designing effective group activities in a variety of subject areas and educational settings; and

6. use a "before-after" example of a group assignment from one of our colleague's classes to illustrate why the effectiveness of group activities is so closely tied to their impact on group cohesiveness.

\section{The Nature of Group Interaction}

Under certain conditions, a high percentage of group members would prefer to sit back and let "someone else" work on their behalf. This phenomenon, which has come to be known as "social loafing" (Latane, Williams \& Harkins, 1979) can be a serious problem in classrooms and workshops because it heavily constrains the interaction necessary for a productive learning environment. Further, if left unchecked, the conditions that produce social loafing can prevent the development of the social fabric that is necessary for effective learning groups. More assertive members will inevitably "take charge" and, by doing so, will both reduce the need for additional input and create a sort of a "caste" system in which quieter members often feel that their ideas might not be welcomed.

We have identified six forces which, unless recognized and dealt with by the instructor or workshop leader, will produce a level of social loafing that will be a serious problem in most learning groups. Three of these have to do with the characteristics of group members. First, some people are naturally resistant to participation (e.g., shy). Second, others prefer to dominate a discussion. Third, members who feel they lack content knowledge of the task at hand are usually reluctant to speak because they are concerned about being seen as incompetent. Two others are especially problematic in newly formed and/or temporary groups: (1) some members are typically more concerned about their own personal image than that of the group and (2) they may see themselves as having little to lose if the group fails to perform 
effectively. Finally, the group task promotes social loafing when it can be completed by one member working alone and/or doesn't require members to reach an agreement (see Figure 1).

The forces that promote social loafing in learning groups, however, can largely be offset by assignments and practices that foster the development of cohesive learning groups. There are two reasons for this. First, as groups become more cohesive, trust and understanding typically build to the point that even naturally quiet members are willing and able to engage in intense give-and-take interactions without having to worry about being offensive or misunderstood (Michaelsen, Watson \& Black, 1989; Watson, Michaelsen \& Sharp, 1991; Watson, Kumar \& Michaelsen, 1993; Michaelsen, Black \& Fink, 1996). Second, a primary characteristic of cohesive groups is that members see their own well being as integrally tied to the success of their group. As a result, members of cohesive groups are often highly motivated to invest personal energy doing group work (Shaw, 1981; Michaelsen, Jones \& Watson, 1993).

\section{FIGURE 1 \\ Forces that Promote Social Loafing}

(Uneven Contributions in Group Discussions)

a Some individuals naturally resist participation (shyness).

a Some individuals prefer to dominate discussions.

a Members may believe they lack the content knowledge required for making a meaningful contribution.

a Members may be concerned about appearing to be disagreeable or overty agressive."

a Members may not be committed to the success of the group."

[- The task may be inappropriate for groups because it:

- can be completed by one or two members working alone.

- does not require members to reach an agreoment.

- These are especially important problems with new groups. 


\section{Characteristics of Learning Tasks that Promote Group Cohesiveness}

The single most effective strategy for eliminating social loafing is to ensure that four key dimensions of the learning tasks cause members to interact in ways that promote the development of cohesive groups. Specifically, the tasks should be explicitly designed to: (1) require a high level of individual accountability for group members and/or workshop participants; (2) motivate a great deal of discussion among group members; (3) ensure that members receive immediate, unambiguous and meaningful feedback (preferably involving direct comparisons with the performance outputs from other groups); and (4) provide explicit rewards for high levels of group performance (see Figure 2).

Ensuring individual accountability. Instructors or workshop leaders often inadvertently foster social loafing by failing to ensure that their group assignments (especially the first one) require input from every group member. The initial assignment is key for two reasons. First, the innate forces against broad-based participation in new groups

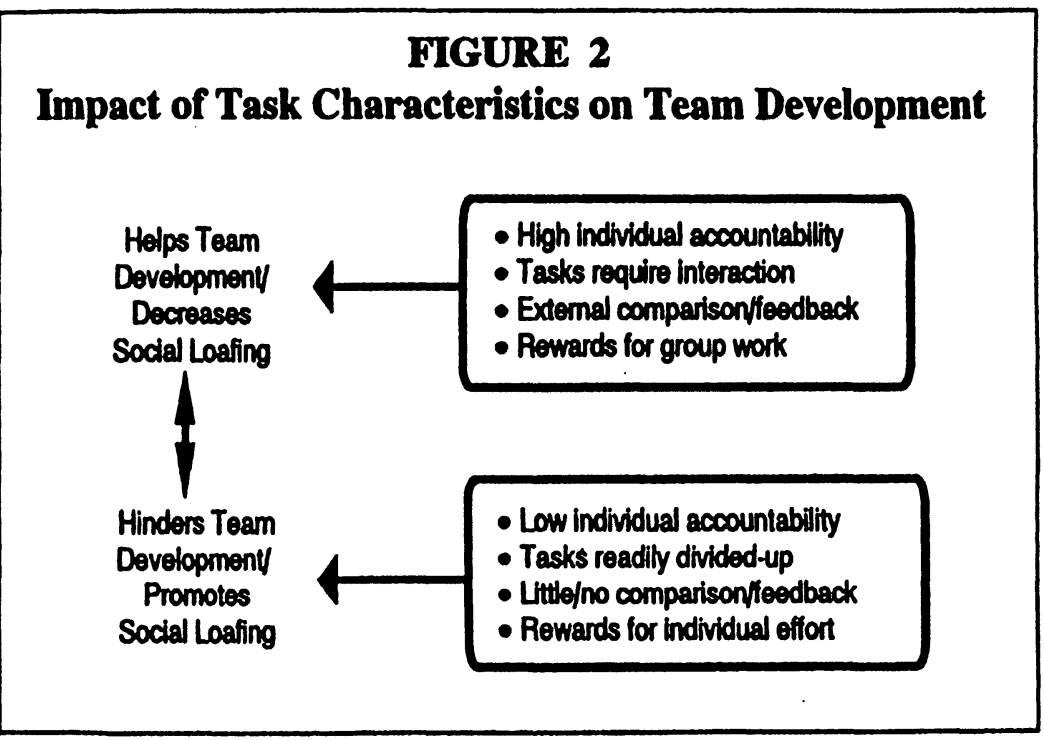


(see Figure 1) are so powerful that they must be offset early on. Second, if the group is even modestly successful with input from only one or two members, then it is highly likely that the group will develop a norm supporting at least partial non-participation of members (Feldman, 1984).

On the other hand, if the task explicitly requires input from group members, then the question of whether their input is needed becomes a moot point. As a result, at least two of the negatives are turned into positives. One is that members are faced with the possibility of being seen in a negative light if they don't contribute. The other is that, because of the additional input, the groups are more likely to succeed, which reinforces a norm that everyone is expected to provide input to the group (Feldman, 1984). These dynamics are two of the main reasons that giving an individual test followed immediately by a group test is such a powerful learning and group-building tool (Michaelsen \& Black, 1994; Michaelsen, Black \& Fink, 1996). Another way to ensure broad-based input in small group discussions is to hand out an individual worksheet and to ask participants to take a few minutes to think through the issues and write down their ideas prior to the start of the group discussions (see the discussion of "Think, Pair Share" in Cottell, Millis \& Engrave, 1996).

Motivating intensive group interaction. The most common cause of social loafing is the use of assignments that can be completed by independent individual work. When the rational way to complete a task is to "delegate" the work to individual members, that is exactly what will happen. Delegating commonly occurs in two situations. One situation is when the assignments are too easy (i.e., group interaction isn't needed). In this case, one member will simply act on behalf of the group. The other situation occurs when the task requires a great deal of writing. Because writing is inherently an individual activity, the only real group activity will be deciding how to divide up the work. When group members work independently, cohesiveness is reduced for at least two reasons. The first reason is that some members always feel like they are having to do more than their fair share (and in most cases, they probably are correct). The other reason is that, depending on the group's performance, the top students are likely to resent having 
to choose between carrying their less able or less motivated peers or risk getting a low grade.

Although a number of different types of tasks will produce high levels of group interaction, a highly reliable "rule-of-thumb" is that assignments increase group cohesiveness (and, over time, eliminate social loafing) when they require members to make a concrete decision based on the analysis of a complex issue: in other words, when we ask students or workshop participants to apply a rule or solve a problem. This type of task typically requires students to use a broad range of intellectual skills including: recognizing and defining concepts, making discriminations, and applying principles or procedural rules (Gagne, 1970). Further, everyone typically has both opportunities and incentives to participate actively in completing the task because of the genuine need for broad-based member input. The net result is that problem-based tasks almost universally immerse students and/or workshop participants in information-rich, give-and-take discussions through which their content learning increases. Further, if the assignment is thoughtfully crafted, they are also likely to learn two important lessons about their group: (1) Other members' input is a valuable resource and (2) we can accomplish something by working together that none of us could have accomplished on our own.

Facilitating external [meaningful] performance feedback. The single most powerful force for the development of group cohesiveness is the presence of an outside influence that is perceived to be threatening to member goals and/or the well-being of the group (Shaw, 1981). Differences among members become less important as they pull together to protect themselves and/or their public image. As a result, providing performance data that allow comparisons with other groups is a very powerful tool for increasing group cohesiveness.

Some assignments are clearly better than others at providing such comparisons. In general, the more assignments provide unambiguous performance feedback (especially if it is in a form that enables direct comparisons with similar groups), the better they are at promoting team development. Further, the more immediate the feedback, the greater its value to both learning and group cohesiveness. By contrast, assignments are likely to limit the development of group cohesiveness (and encourage social loafing) if they force groups to do the majority 
of their work in the absence of feedback. When groups have no way of knowing how they are doing (e.g., when groups are asked to produce some sort of a complex "product" such as a group paper), members are likely to experience a great deal of stress in working with each other. For example, differences in members' work styles often produce a great deal of tension in the group. Members who have a strong preference for a systematic and orderly approach and have time to work on the project often become so anxious that they alienate their peers who either have different time pressures or who feel they do better work when they are faced with a performance deadline.

Rewarding group success. Although it would be wonderful if students or workshop participants would complete group assignments because of a love of learning, if we fail to create a situation in which doing good work as a group "pays off" in some meaningful way, we are, in effect, asking them to behave irrationally. One obvious way to use group rewards as a means of building group cohesiveness is to include group performance in our grading system. Failing to do so will greatly increase the probability that group cohesiveness will be blocked by the fact that students will correctly see themselves competing with other members of their own group.

Including group performance in the grading system is not, however, the most effective way to use rewards for building groups (and minimize social loafing) for three reasons. First, unless the grading system also promotes individual accountability (e.g., grading individual work that prepares students for group work, using a peer evaluation system, etc.), social loafing can still become a serious problem. Second, groups often contain members with very different needs what may be an acceptable grade for one student might be a disaster for another. Third, giving grades isn't even a possibility in workshops and many other educational settings in which we should be using group work.

In our judgment, the reward that offers the greatest potential for both classrooms and workshops is the basic human need for social validation. Everyone wants to feel they can offer something of value to others. Thus, by creating a situation in which the output from group work will be scrutinized and challenged by peers from other groups, 
we are creating an environment that promotes both group cohesiveness and learning.

The best and the worst. Based on our experience, the best activity available for building group cohesiveness and minimizing social loafing is the Readiness Assurance Process which constitutes the first four steps in the learning activity sequence in Team Learning (Michaelsen, Watson \& Schraeder, 1985; Michaelsen, 1992; Michaelsen \& Black, 1994) and the worst activity is group term papers. The Readiness Assurance Process is used at the very beginning of each major instructional unit (i.e., prior to any lectures) to ensure that students master basic course content. It involves four steps: (1) individual students complete a test over a set of pre-assigned readings and turn in their answers; (2) groups then re-take the same test and turn in their consensus answers for immediate scoring (group scores are posted on the board to provide immediate cross-group comparisons), (3) groups are given time to re-study their assigned readings to prepare written appeals for any questions they have missed; and (4) the instructor provides input that is specifically focused on remediating student misunderstandings that have come to light in the previous three steps of the process. The power of the Readiness Assurance Process comes from the fact that its activities, in combination, clearly meet all four of the criteria for building groups (see Figures 2 and 3).

By contrast, group term papers seldom provide any support for building group cohesiveness and almost universally result in at least the perception of social loafing. Because writing is inherently an individual activity, the rational way to accomplish the overall task is to divide up the work so that each member independently completes part of the assignment (usually the part that he or she already knows the most about). As a result, there is seldom any significant discussion after the initial division of labor, and feedback is generally unavailable until it is too late to create either individual accountability or meaningful comparisons with other groups. Further, under these conditions, having part of the grade based on group performance is as much of a negative as a positive. Members are well aware that the failure of any member of the group could force the rest to accept a low grade or engage in a last-minute attempt to salvage a disaster. In fact, highachieving students often express the feeling that getting an acceptable 
grade on a group term paper feels like having crossed a freeway during rush hour without being run over.

Differences in group process that result from the specific requirements of learning tasks not only affect group cohesiveness; they also have a profound impact on learning. Before we try to link group processes and learning, however, we will briefly set the stage by reviewing some of what is known about "ways" in which we learn, i.e., process information. As a result, the following paragraphs focus on cognitive processes that come into play as we take-in, store, and use ideas and information.

\section{Learning Processes: Implications for Assignment Design}

On the surface, what we know would seem to be the sum total of the information to which we have been exposed. Taking in information

\section{FIGURE 3 \\ Impact of the Readiness Assurance Process.}

Individual Accountability from:

a Completing individual exam over assigned readings prior to group exam (counts toward the course grade).

- Revealing/defending individual answers during the group exam.

a Preparing written appeals to justify their point of view on questions on which they influenced the group to select an incorrect answer.

Intense Give-and-take Group Discussion from:

- Having to agree on a group answer on each test question.

- Agreeing on a rationale for witten appeals justifying their point of view on questions incorrectly answered during the group test.

External [Meaningful] Performance Feedback from:

- Immediate scoring of individual and group exams.

- Posting group test scores to provide external comparisons.

- Feedback and corrective input from instructor.

Reward for Group Success from:

a Group exam scores count toward course grade.

a Public awareness of group exam scores. 
is, however, only part of the learning process (Bruning, Schraw \& Ronning, 1994). Information that is taken in and stored in short-term memory decays very rapidly. Thus, from a practical standpoint, what we "know" is more a function of our ability to retrieve and use the information than the sum total of the information that we have taken in.

Impact of what we know. Our ability to learn is profoundly affected by both information to which we have previously been exposed and the way this information is stored in our long-term memory. Most importantly, our capability to learn depends on the extent to which the related components of our memory are clustered into well organized structures (i.e., sometimes referred to as schemata) (see Anderson, 1993; Mandler, 1984; Bruning et al., 1994). These information structures are important because they provide "hooks" that help establish links between new information that is related to what we already "know" and between the individual components of our existing structures. In addition, the structures provide a backdrop that helps us to recognize what we don't know (i.e., information that doesn't "fit').

Information structures and learning. What we "know," then, is largely a function of the number, complexity and inter-connectedness of the information structures in our long-term memory and, for practical purposes, consists of the information that we are able to retrieve and use. Significant learning has taken place when we increase the amount of information we are able to retrieve and use. This usually occurs when new information motivates us to: (1) add to existing structures, (2) establish new structures, or (3) establish new links within or between existing structures.

Elaborative Rehearsal. If a learning activity exposes us to new information that neatly connects to a "hook" in one of our information structures, then it is simply "attached" to the appropriate link. If new information appears to conflict with existing groupings, the learning process takes a very different, but even more beneficial, course. Initially, we will "search through" our long-term memory to review the linkages upon which the apparent conflict is based. If this review confirms the existence of a conflict, we will be in a state of discomfort until we find a harmonious accommodation. If none is found and the information's credibility is sustained, we are motivated to eliminate 
the conflict by modifying and/or adding to existing information groupings. This memory retrieval and examination process, called elaborative rehearsal (Craik \& Lockhart, 1986), facilitates learning because each stage has a positive impact on our long-term memory. As a result, the greater the extent to which an assignment exposes students or workshop participants to credible information that conflicts with their existing information structures, the greater its impact on their longterm memory.

Promoting the development of higher-level cognitive skills. The importance of providing opportunities for elaborative rehearsal is dramatically illustrated by a series of studies involving learning groups that are summarized in Slavin (1995). In all of the studies, students were divided into four member "Jigsaw" groups. Each member was assigned to become a subject-matter expert with respect to one of four areas and then given the opportunity to teach the material to the other members of his or her Jigsaw team. In most instances, students in Jigsaw groups scored higher on an overall summative test than students from a control group who had been taught with a more traditional method. The positive benefits of the Jigsaw activity, however, were primarily due to students' mastery of the material that they had "taught" to their peers. Hearing someone else explain a set of concepts (i.e., listening to a lecture) had a minimal positive effect as compared to the impact of having to synthesize the information, organize a presentation and present the information to a group of peers.

In two other studies, Lazarowitz (1991) and Lazarowitz and Karsenty (1990) added an additional learning task for the Jigsaw groups. After the Jigsaw peer instruction, each of the groups was given a discovery-oriented problem to solve that required actively using information presented by each of the four subject-matter experts. The most significant finding from these studies was that requiring students to engage in higher-level thinking (Gagne, 1970) increased students' ability to recall and use the information that was originally presented by the other subject-matter experts.

Based on the overall results of the Jigsaw studies, it appears that listening to another peer in a learning group, even when combined with the opportunity to ask clarifying questions, produces only modest gains in long-term memory. On the other hand, learning activities that 
require higher-level thinking skills (Gagne, 1970), such as acting in a teaching role (see also Bargh \& Schul, 1980) or using concepts to solve a discovery-oriented problem, produce substantially greater long-term gains in students' ability to recall and use course concepts. Other types of learning activities that focus on using higher-level thinking skills have also been shown to produce similar gains compared to simple cognitive tasks, such as listening to lectures or going over one's notes. These include taking tests (see Nungester \& Duchastel, 1982), writing "minute papers"(Wilson, 1986), and being exposed to opposing views on a subject then having to resolve the conflicts in the process of making a decision (Smith, Johnson \& Johnson, 1981). In combination, these findings convincingly argue that the long-term impact of group work will be much greater if group assignments go beyond simply exposing learners to new information by requiring them to actively engage in the use of higher-level cognitive skills.

\section{Phrasing Assignments to Promote the Use of Higher-level Cognitive Skills.}

The degree to which assignments stimulate higher-level cognitive skills (i.e., elaborative rehearsal) is largely a function of what we ask students to "produce." For example, suppose an English composition instructor wanted to ensure that his or her students were able to

\section{FIGURE 4 \\ Working Assisgnments to Promote Higher-level Cognitive Skills}

"Mako-ollios"

1. List the 'mistakes' that writers frequenty make that detract from their efforts to witte in active volice."

"Mako-echolec"

2. Read the following passage and identity a sentence that is a clear example of: a) active, and b) passive voico."

"Mako-erepoctice-cholce"

3. Read the following passage and identity the sentence in which passive 'volice' is used most appropiately." 
recognize the effective use of active vs. passive voice in written communication. Three alternative versions of the assignment are shown in Figure 4 (see also Michaelsen, Black \& Fink, 1996).

In the examples shown in Figure 4, the order of the tasks reflects the degree to which they would require the use of higher-level cognitive skills. It is unlikely that alternative \#1 would stimulate higherlevel thinking because students could "make-a-list" by simply extracting items from one or more reference sources and recording them in another location. Assignment \#2 is considerably better. Having to "make-a-choice" would require students to examine critically the sentences in the sample passage and use the criteria that define active vs. passive voice to identify examples of active and passive voice. Alternative \#3 would provide the most practice using higherlevel cognitive skills for two reasons. First, students could not complete task \#3 unless they could also complete tasks \#1 and \#2. Second, as is typical of "make-a-specific-choice" assignments, picking a single best example of correct use of passive voice would require students to use/develop a number of higher-level cognitive skills. At a minimum, these would include making multiple comparisons and discriminations, analysis of content information, and verification of rule application (see Gagne, 1970).

\section{Implications for Effective Group Assignments}

Although "make-a-specific-choice" assignments (see Figure 4) are beneficial for individual students working alone, they produce the greatest gains in conjunction with learning groups. In part, this occurs because students/workshop participants have an additional source of motivation to take the assignment seriously. In addition, group interaction provides two additional opportunities to stimulate active learning. One is during discussions within the groups. The other occurs during subsequent class discussions (i.e., between groups). Further, when used in a group context, "Make-a-specific-choice" assignments increase learning in each step of the process and set the stage for greater learning in the next (see Figure 5).

Individual preparation for group work. As long as group members are given the assignment as preparation for group work (e.g., in the 
example from Figure 4, having everyone read the same passage and select the sentence in which passive voice is used most appropriately), having students make a specific choice ensures that members will be individually far more accountable for having engaged in higher-level thinking than is the case with "make-a-list" assignments for three reasons. First, learners have to use higher-level thinking skills in order to make choices (see Gagne, 1970). Second, members expect to be asked to share their choice with their group. Third, they are also aware that, unless the group is in complete agreement, the differences will be so evident that proponents of each of the alternatives will almost certainly be asked to explain the reasons behind their choices. As a

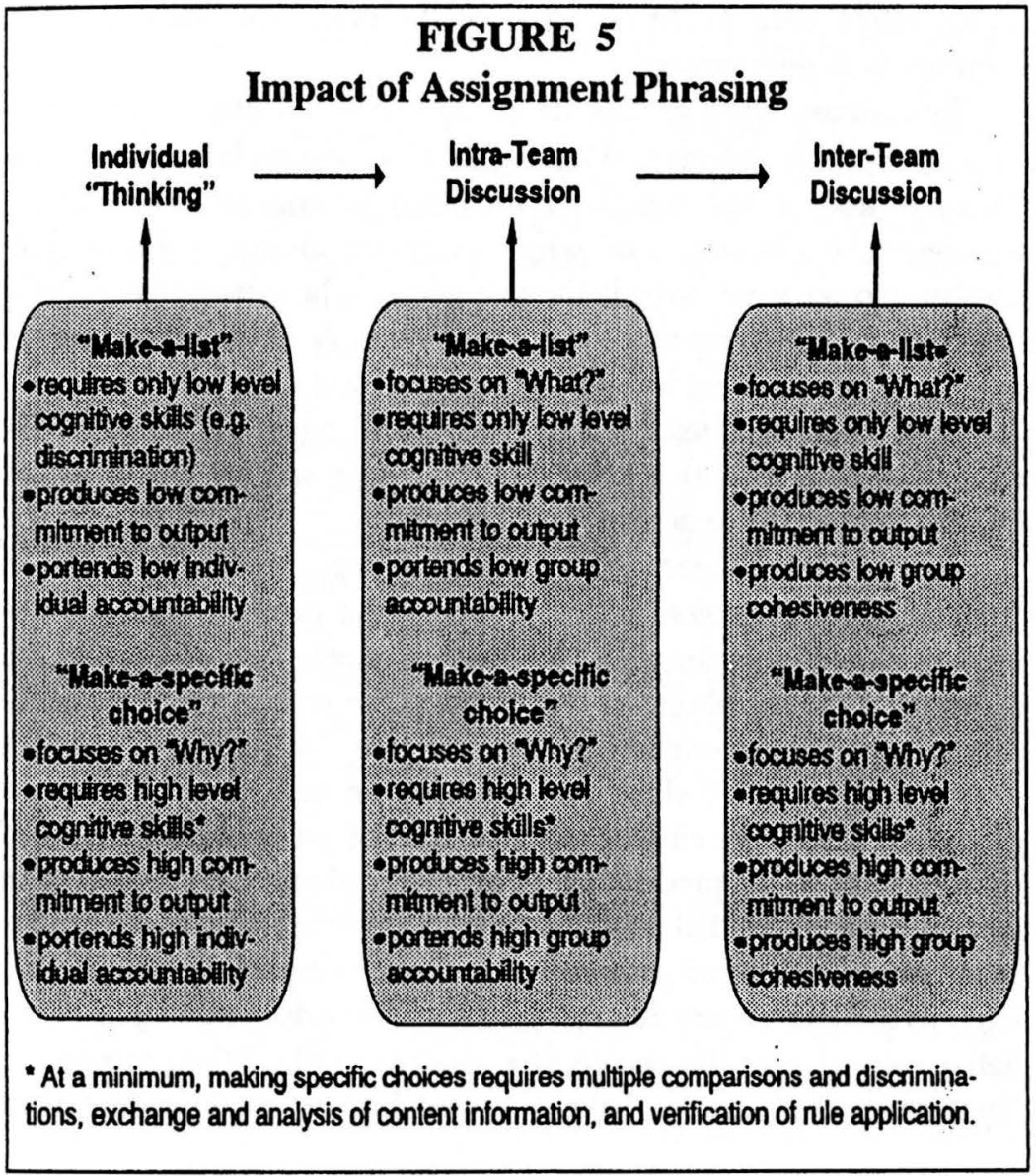


result, "make-a-specific-choice" assignments motivate most students/workshop participants to enter the group discussion with a clearly defined position and the ability to defend it (see Figure 5).

Discussions within groups. The difference between "make-a-list" and "make-a-specific-choice" assignments is even more evident in intra-team discussion. Listing possibilities tends to be a low energy team task for several reasons. One is that a search for what should be on a list focuses on quantity rather than quality. Another is that once several items go on the list, it is easy for quieter and/or less self-assured participants to get "off the hook" by saying that their ideas are already listed. Finally, making a list seldom leads to a feeling of pride in the group output because the majority of the items are likely to be in common with other groups.

By contrast, when groups are asked to select a single best choice based on specific criteria and know that other groups have been given the same assignment, members are likely to engage in an intense give-and-take discussion of why any given choice is better than another. No one wants to be in the only group to have made a particular choice (e.g., Which sentence is the best example of the correct use of passive voice?) and not be able to present a clear and cogent rationale for the position. As a result, most groups will engage in "make-a-specific-choice" tasks with a great deal of energy and are also likely to be willing and able to defend their choices.

Discussions between groups. Group assignments phrased in "make-a-specific-choice" terms produce their greatest gains in subsequent class discussions (i.e., between-groups). Two of the benefits come from the simplicity of the output. One is that they invariably promote group accountability because any differences between groups are absolutely clear. For example, an assignment that asked groups to select the single best example of an appropriate use of passive voice would produce a much more productive class discussion than an assignment that asked groups to identify examples of appropriate use of active and passive voice. Comparing "best examples" is likely to produce a more intense and informative discussion than either listing examples or the choice of a clear example. When comparing "best examples," groups have a vested interest in defending their 
position and the discussion will focus on the reasons that one choice is better than another.

By contrast, group assignments that result in either lists or nonspecific choices often result in low-energy class discussion and allow relatively poor group analyses to go unchallenged. The lack of energy results from the fact that groups tend to be far more interested in their own work than that of other groups. Poor analysis often goes unchallenged because: (1) having students/workshop participants either make a list or a non-specific choice is likely to produce so much data that the task of finding something to challenge can be quite difficult and (2) the absence of clear comparisons allows groups to overlook inconsistencies in both their own and other groups' analyses.

Group cohesiveness. Another important benefit of properly designed "make-a-specific-choice" group assignments is their positive impact on cohesiveness. Because reaching consensus on a difficult choice requires a great deal of thought and effort, students/workshop participants intuitively realize that differences between teams represent an important source of feedback. Thus, because differences between team choices are so clear, they represent a significant external threat. By contrast, "make-a-list" assignments seldom promote group cohesiveness because the output is poorly suited for inter-group comparisons. This becomes most apparent when groups share the results of their discussions. Even though groups generally do a pretty good job of making lists, there is almost always a "nose-dive" in the energy level when the groups "report" to the class. In fact, simply getting students/workshop participants to pay attention to each other as representatives go over each item in their list can be a serious problem. Differences that groups might otherwise take pride in and be motivated to defend are both obscured and diminished in significance by the sheer volume of data.

\section{Assignments that Facilitate Inter-group Comparisons.}

There are two keys to ensuring that "make-a-specific choice" assignments facilitate inter-group comparisons. One is keeping the "output" as simple as possible. The other is organizing the inter-group 
sharing process to minimize the amount of time used in a lecture-like mode (i.e., a series of representatives giving a report of what happened in their group).

For example, suppose a marketing instructor wanted to create a "make-a-specific choice" assignment that would ensure him or her that students understood the key variables that should be considered in selecting a site upon which to locate a new business. One way to word the assignment would be, "Select what you think would be the ideal site to locate a new dry cleaning establishment in (i.e., filling in the name of a specific city about which students could gain access to relevant data). Identify and be prepared to explain the rationale for the single most important site selection factor that led to your decision (Michaelsen, Black \& Fink, 1996)."

Although the assignment involves making a specific choice, the degree to which it would support inter-group comparisons depends on both the specific "product" that was used to represent their choice and the nature of the group reporting process. One common approach would be to assign each of four groups to make a 10-minute presentation revealing their chosen location and the rationale for selecting it followed by a few minutes for questions and class discussion.

Alternatively, the instructor could require students to come to class having made their choice and, instead of using class time for presentations, he or she could:

1) Give each group a post-it-note with their group number on it, a felt-tipped marker, and a legal-sized sheet of paper.

2) Allow 5-minutes to decide on and record their single most important reason for their decision.

3) Require groups (after 5 minutes) to place their post-it on their selected location on a city map attached to the classroom wall.

4) Allow groups 10 minutes to formulate questions they would like to ask the other groups.

5) Use the remainder of the class for questions and discussion.

In this example, the "post-it-note" version of the assignment would provide far more explicit intergroup comparisons. With presentations, the differences are obscured by three factors. First, the sheer volume of data in three other 10-minute presentations makes it difficult for students to keep track. Second, the relevant facts are presented 
over a 40-minute span. As a result, the key points will be temporally separated by far less significant information. Third, because the groups are likely to use a variety of presentation modes, establishing links between key ideas is likely to seem like comparing apples and oranges. By contrast, using the "post-it-note" approach ensures that, instead of being overwhelmed with data, students are exposed to a simultaneous, common, permanent, and highly visual representation of only the essential data: 1) the proposed locations and 2) the foundation of each group's rationale for their choice. Further, they have a designated time to process carefully and digest the information in an integrated way.

\section{A Checklist for Effective Group Activities.}

Probably the most important key in designing effective group assignments is viewing the entire context within which they will be used. This includes taking into account the developmental level of the groups, individual preparation for group work, discussions within groups, post-group class discussions, and the extent to which the group will work together again. The following checklist (see Figure 6) provides prompts for taking these factors into account as you evaluate and/or design group assignments.

\section{Making Good Group Assignments into Great Ones}

Regardless of its primary intent, every learning activity affects learning in two very different ways. First, the specific characteristics of the activity determine how much active learning can be achieved by its use. Second, each activity inherently fosters (or inhibits) the peer interactions that have a major impact on team development. Fưrther, modifying an activity in an attempt to change the impact on either dimension is likely to affect the other.

For example, we have an agronomist colleague who wants his students to develop the ability to recognize the weeds that commonly infest turf grass lawns in our region. Initially he used an assignment that required groups to "identify and appropriately tag an example of 
each weed variety growing in plot \#1 [which he had laid out] on the lawn on the east side of this building". The assignment worked quite well, but he decided to modify the group portion of the activity in an attempt to increase its value for building cohesiveness. The revised assignment uses 5 plots (one for each group in the class) and requires an additional 20 minutes to complete. During the first 10 minutes, the group members, working individually within their team's plot, find and temporarily tag an example of each weed variety. During the next 20 minutes, the groups: (1) agree on (and permanently tag) a sample of each weed variety in their plot (and receive 10 points for each

\section{FIGURE 6 \\ Criteria for Effective Group Assignments}

\section{Prior to Group Discusesions:}

a Are group members required to use newly acquired concepts to make a specific choice, individually and in writing? (Note: This individual accountability is especially important in newty formed group.)

During Discuseions within Groups:

- Are groups required to share members' individual choices and agree (i.e., reach a group consensus) on a specific choice?

- Will the discussion focus on Why?" (and/or "How?")

Will the groups' choice(s) be represented in a form that enables immediate and direct comparisons with other groups"?

During Discusesions between Groups:

Are group decisions reported simultaneousty"?

Do group "reports" focus attention on the absolutely key issues"?

Are groups given the opportunity to digest and refiect on the entire set of "reports" before total class discussion begins?

Will the discussion focus on Why?" (and/or "How?")

The more "Yes" answers, the better. If the answer to all eight questions is

"Yes," the assignment will effectively promote both leaming and group development.

The form in which individual and group choices are represented largely determines the dynamics of the discussions that follow. Both individual reports to groups and group reports to the class should be as absolutely succinct as possible. One-word reports are the very best (e.g., yes/no, best/worst, up/down/no change, etc.) because they invariably stimulate a discussion of why one choice is better than another. 
correctly tagged weed variety) and (2) prepare for a "Weed Finders' Challenge" (WFC). During the WFC, groups have 5 minutes to examine each others' plots and "challenge" incorrectly tagged weeds. If their challenge is valid, they receive 10 bonus points, but if the challenge is bogus, they lose 10 points to the group who elicited the challenge.

Although the changes were modest in nature, they produced positive changes in all four of the factors that affect group cohesiveness (see Figure 2). The assignment now provides rewards for group work (the opportunity to earn points for correctly tagging weeds and extra points by successfully challenging other groups). The assignment provides external comparison/feedback (by giving other groups the opportunity to challenge each other). The assignment produces high levels of group interaction (reaching consensus on your own samples and preparing members to scout other plots). Finally, the assignment promotes individual accountability on both ends (individual tagging prior to group work and individuals serving as scouts during the WFC). As a result, the assignment is much more effective in building group cohesiveness. Groups typically use the first half of their time to make sure they have a correctly tagged sample of each weed variety. Then they turn their attention to preparing for the WFC by: (1) preparing members to scout for a potential challenge because they don't have time to go to each of the other plots as a group and (2) shifting their tags to atypical examples of the weed varieties in an attempt to "set-up" other groups for a bogus challenge.

Even though the impact on cohesiveness has been highly positive, the impact on learning has been even greater. The knowledge that they will have to work on their own causes group members to be more serious about advance preparation. Thus, members start out with a reasonably high level of understanding that is further enhanced during the group discussions in preparation for the Weed Finders' Challenge.

\section{Energy - the Acid Test for Effective Group Activities}

Our colleague's experience with modifying the group assignment for his agronomy class illustrates two key concepts about effective 
group assignments. First, the best way to increase the effectiveness of group assignments is to focus on increasing the extent to which they build group cohesiveness. Assignments simply will not increase group cohesiveness unless they produce a great deal of task-focused energy. Thus, if you ask yourself the question, "How can I change this assignment so that it will increase group cohesiveness?," you are also asking, "How can I change this assignment so that students/workshop participants will commit a higher level of energy to this learning task?" Second, the single best indicator of the effectiveness of a group assignment is what happens when groups share the results of their discussions with the class as a whole. The higher the energy (i.e., the extent to which groups are interested in and willing to spontaneously challenge each other's thinking and defend their own), the more confident you can be that: (1) they have taken their group work seriously and (2) their ability to tackle even more difficult learning tasks has been significantly enhanced.

\section{Conclusion}

Overall, we hope that four messages have come through in this paper. First, group activities and assignments can be a highly effective tool for developing both students' mastery of basic conceptual material and their higher-level thinking and problem-solving skills. Second, the vast majority of student or workshop participants' dysfunctional behaviors (e.g., social loafing, one or two members dominating the discussion, etc.) and complaints (e.g., having to carry the dead wood, the instructor isn't teaching, etc.) are the result of bad assignments not bad learners. Third, the key to designing effective group assignments is to maximize the extent to which the learning tasks promote the development of cohesive learning groups. Finally, the single best way to gauge the effectiveness of group assignments is to observe the level of energy that is present when the results of the small group discussions are reported to the class as a whole.

\section{References}

Anderson, J. R. (1993). Problem solving and learning. American Psychologist, 48, 35-44. 
Bargh J. A., \& Schul, Y. (1980). On the cognitive benefits of teaching. Journal of Educational Psychology, 74, 593-604.

Bruning, R. H., Schraw, G. J, \& Ronning, R. R. (1994). Cognittive psychology and instruction (2nd ed.). Englewood Cliffs, NJ: Prentice-Hall.

Cottell, P., Millis, B. J., \& Engrave, R. W. (1996). Cooperative learning techniques and reaching notes: Financial accounting. Cincimnati, OH: Southwestern College Publishing.

Craik, F. L. M., \& Lockhart, R. S. (1986) CHARM is not enough: Comments on Eich's model of cued recall. Psychological Review, 93, 360-364.

Feldman, D. (1984). The development and enforcement of group norms. Academy of Management Review, 9, 47-53.

Gagne, R. M. (1970). The conditions for learning (2nd ed.). New York: Holt, Rinehart \& Winston.

Latane, B., Williams, K., \& Harkins, S. (1979). Many hands make light the work: The causes and consequences of social loafing. Journal of Personality and Social Psychology, 37, 822-832.

Lazarowitz, R. (1991). Learning biology cooperatively: An Israeli junior high school study. Cooperative Learning, 11, 19-21.

Lazarowitz, R., \& Karsenty, G. (1990). Cooperative learning and student's self-esteem in tenth grade biology classrooms. In S. Sharon (Ed.), Cooperative learning theory and research (pp. 143-149). New York: Praeger Publishers.

Mandler, J. M. (1984). Stories, scripts, and scenes: Aspects of schema theory. Hillsdale, NJ: Lawrence Erlbaum.

Michaelsen, L. K. (1992). Team learning: A comprehensive approach for harnessing the power of small groups in higher education. In D. H. Wulff, \& J. D. Nyquist (Eds.), To Improve the Academy, Vol. 11 (pp. 107-122). Stillwater, OK : New Forums Press and the Professional and Organizational Development Network in Higher Education.

Michaelsen, L. K., \& Black, R. H. (1994). Building learning teams: The key to hamessing the power of small groups in higher education. Collaborative Learning: A Sourcebook for Higher Education, Vol. 2 (pp. 65-81). State College, PA: National Center for Teaching, Learning and Assessment.

Michaelsen, L. K., Black, R. H., \& Fink, L. D. (1990). What every faculty developer needs to know about learning groups. In Richlin, L. (Ed), To Improve the Academy, Vol. 15 (pp. 31-58). Stillwater, OK: New Forums Press and the Professional and Organizational Development Network in Higher Education.

Michaelsen, L. K. , Jones, C. F., \& Watson, W. E. (1993). Beyond groups and cooperation: Building high performance leaming teams. In D. L. Wright, \& J. P. Lunde (Eds.), To Improve the Academy, Vol. 12 (pp. 127-146). Stillwater, OK : New Forums Press and the Professional and Organizational Development Network in Higher Education.

Michaelsen, L. K., Watson, W. E., \& Black, R. H. (1989). A realistic test of individual versus group consensus decision making. Journal of Applied Psychology, 74, 834839. 
Michaelsen, L. K., Watson, W. E., \& Schraeder, C. B. (1985). Informative testing: A practical appraach for tutoring with groups. Organizational Behovior Teaching Review, 9, 18-33.

Nungester, R. J., \& Duchastel, P. C. (1982). Testing versus review: Effects on retention. Journal of Applied Psychology, 74, 18-22.

Shaw, M. E. (1981). Group dynamics: The psychology of small group behavior (3rd ed.) New York: McGraw-Hill.

Slavin, R. E. (1995). Cooperative learning (2nd ed.). Boston, MA: Allyn \& Bacon.

Smith, K., Johnson, D. W., \& Johnson, R. T. (1981). Can conflict be constructive? Controversy versus concurrence seeking in learning groups. Journal of Educational Psychology, 73, 651-663.

Watson, W. E., Kumar, K., \& Michaelsen, L. K. (1993). Cultural diversity's impact on group process and performance: Comparing culturally homogeneous and culturally diverse task groups. The Academy of Management Journah 36, 590-602.

Watson, W. E., Michaelsen, L. K., \& Sharp, W. (1991). Member competence, group interaction and group decision-making: A longitudinal study. Journal of Applied Psychology, 76, 801-809.

\section{Contact:}

Larry K. Michaelsen

Division of Management

University of Oklahoma

206 Adams Hall

Norman, OK 73019-0450

(405) 325-5692

(405) 325-1957 FAX

Imichael@uoknor.edu

Larry K. Michaelsen (Ph.D. University of Michigan) is David Ross Boyd Professor of Management at the University of Oklahoma and former editor of the Journal of Management Education. His primary research interests are the dynamics of problem-solving groups and the use of group-based activities for teaching critical thinking. He has received numerous awards for his teaching and for his pioneering work with Team Learning, a comprehensive small-group based instructional process that is now being used in over sixty disciplines and on over 100 college campuses world-wide.

L. Dee Fink (Ph.D. University of Chicago) has served as Director of the Instructional Development Program at the University of Oklahoma since 1979. His primary interests are evaluation of classroom instruction and developing methods for increasing students' higher-level learning. 
Arletta Knight (Ph.D. University of Oklahoma) is Assistant to the Director of the Instructional Development Program at the University of Oklahoma. Her primary interests are instructional communication in higher education, educational evaluation, and developing methods for increasing students' higher-level leaming. 